\title{
Impaired Antibody Response Causes Persistence of Prototypic T Cell-Contained Virus
}

\author{
Andreas Bergthaler ${ }^{1,2 * a a}$, Lukas Flatz ${ }^{1,2 \odot a b}$, Admar Verschoor $^{2 \odot a c}$, Ahmed N. Hegazy ${ }^{2 a d}$, Martin Holdener ${ }^{2 a e}$, \\ Katja Fink ${ }^{2 a f}$, Bruno Eschli ${ }^{2}$, Doron Merkler ${ }^{3}$, Rami Sommerstein ${ }^{1,4}$, Edit Horvath ${ }^{2}$, Marylise Fernandez ${ }^{1,4}$, André Fitsche ${ }^{5}$, \\ Beatrice M. Senn ${ }^{20 g}$, J. Sjef Verbeek ${ }^{6}$, Bernhard Odermatt ${ }^{5}$, Claire-Anne Siegrist ${ }^{1,4,7}$, Daniel D. Pinschewer ${ }^{1,2,4 *}$ \\ 1 Department of Pathology and Immunology, University of Geneva, Geneva, Switzerland, 2 Institute for Clinical Pathology, University Hospital of Zurich, Zurich, Switzerland, \\ 3 Department of Neuropathology, Georg-August-University Goettingen, Goettingen, Germany, 4 WHO Collaborating Centre for Neonatal Vaccinology, University of Geneva, \\ Geneva, Switzerland, 5 Institute for Clinical Pathology, University Hospital of Zurich, Zurich, Switzerland, 6 Department of Human Genetics, Leiden University Medical Center, \\ Leiden, The Netherlands, 7 Department of Pediatrics, University of Geneva, Geneva, Switzerland
}

CD8 T cells are recognized key players in control of persistent virus infections, but increasing evidence suggests that assistance from other immune mediators is also needed. Here, we investigated whether specific antibody responses contribute to control of lymphocytic choriomeningitis virus (LCMV), a prototypic mouse model of systemic persistent infection. Mice expressing transgenic B cell receptors of LCMV-unrelated specificity, and mice unable to produce soluble immunoglobulin $\mathrm{M}$ (IgM) exhibited protracted viremia or failed to resolve LCMV. Virus control depended on immunoglobulin class switch, but neither on complement cascades nor on Fc receptor $\gamma$ chain or Fc $\gamma$ receptor IIB. Cessation of viremia concurred with the emergence of viral envelope-specific antibodies, rather than with neutralizing serum activity, and even early nonneutralizing IgM impeded viral persistence. This important role for virus-specific antibodies may be similarly underappreciated in other primarily $\mathrm{T}$ cell-controlled infections such as HIV and hepatitis C virus, and we suggest this contribution of antibodies be given consideration in future strategies for vaccination and immunotherapy.

Citation: Bergthaler A, Flatz L, Verschoor A, Hegazy AN, Holdener M, et al. (2009) Impaired antibody response causes persistence of prototypic T cell-contained virus. PLoS Biol 7(4): e1000080. doi:10.1371/journal.pbio.1000080

\section{Introduction}

Infections associated with persistent viremia include human immunodeficiency virus (HIV) and the hepatitis B and $\mathrm{C}$ viruses (HBV, HCV), which affect more than 500 million people worldwide. However, available options to prevent and treat particularly HIV and HCV are unsatisfactory. To refine existing strategies aimed at combating these devastating epidemics, and to help direct future efforts, a better understanding of the immune effector pathways preventing viral persistence is of particular importance.

For almost a century, lymphocytic choriomeningitis virus (LCMV) infection of mice has served as a primary model to study basic mechanisms of the virus-host relationship in persistent infection [1]. It has led to the discovery of several essential concepts [2], including MHC restriction of $\mathrm{T}$ cells, viral mutational escape from CD8 cytotoxic T cells (CTL), CTL dysfunction in persistent infection and MHC linkage of virus control. LCMV neutralizing antibody (nAb) responses typically appear late and remain relatively weak [1]. Accordingly, the key role of CTL in controlling and resolving systemic persistent infections has initially been described for LCMV [3-5] with subsequent extension of the concept to important human pathogens such as HIV and HCV. Declining viremia in HIV coincides with the appearance of antiviral CD8 T cells [6,7], and the concept of CTL-mediated HIV control was further strengthened by the association of "protective" HLA molecules with long-term nonprogression in many so-called "elite controllers" [8]. In addition, experimental depletion of CD8 T cells in simian immunodeficiency virus (SIV)-infected macaques also underlined the importance of CTLs in the control of acute, as well as long- term infection [9-11]. Analogous observations were made in HBV- and HCV-infected monkeys [12,13]

Apart from the virtually undisputed contribution of CTLs, evidence has accumulated to suggest that other mechanisms of immune defense are also needed to contain or resolve

Academic Editor: Sarah Rowland-Jones, Weatherall Institute of Molecular Medicine, United Kingdom

Received August 18, 2008; Accepted February 24, 2009; Published April 7, 2009

Copyright: (C) 2009 Bergthaler et al. This is an open-access article distributed under the terms of the Creative Commons Attribution License, which permits unrestricted use, distribution, and reproduction in any medium, provided the original author and source are credited.

Abbreviations: AID, activation-induced cytidine deaminase; $B C R, B$ cell receptor; $\mathrm{CTL}$, cytotoxic T lymphocyte; GP, glycoprotein; HCV, hepatitis $\mathrm{C}$ virus; HIV, human immunodeficiency virus; IgM, immunoglobulin $M$; LCMV, lymphocytic choriomeningitis virus; nAb, neutralizing antibody; non-nAb, nonneutralizing antibody; PFU, plaque-forming unit; $\mathrm{QM}$, quasimonoclonal

* To whom correspondence should be addressed. E-mail: andreas.bergthaler@ gmail.com (AB); daniel.pinschewer@gmx.ch (DDP)

ه These authors contributed equally to this work.

aa Current address: Institute for Systems Biology, Seattle, Washington, United States of America

ab Current address: Vaccine Research Center, National Institutes of Health Bethesda, Maryland, United States of America

ac Current address: Institute for Medical Microbiology, Immunology and Hygiene, TU Munich, Munich, Germany

ad Current address: German Rheumatism Research Center Berlin, Berlin, Germany ae Current address: Pharmacenter, Johann Wolfgang Goethe University, Frankfurt am Main, Germany

of Current address: Novartis Institute for Tropical Diseases, Singapore, Singapore ag Current address: Intercell AG, Vienna, Austria 


\section{Author Summary}

Persistent viruses such as hepatitis C virus (HCV) or HIV can defeat the body's defense system and cause devastating epidemics worldwide. Recent attempts at vaccinating against HIV have relied on the induction of specific antiviral killer T lymphocytes but have failed to confer protection on the host. Better knowledge about how a successful defense should operate is therefore essential for developing and refining new vaccines. Here, we have used a prototypic mouse model to investigate basic defense mechanisms required to eliminate persisting viruses. Experiments in several genetically engineered mouse models show that contrary to common belief, not only antiviral killer $T$ cells, but also antibodies (produced by B cells), are needed to prevent a virus from persisting in its host. These findings suggest that induction of antibodies, along with antiviral killer T lymphocytes, should be envisaged when devising new strategies for vaccinating against HIV or HCV.

systemic persistent virus infection. For instance, "protective" HLA alleles are also found in up to one third of individuals with poor or undetectable immune control of HIV infection $[14,15]$, suggesting that even potent CD8 T cell responses are insufficient for HIV control. Conversely, many "elite controllers" lack any of the known "protective" alleles [15]. Moreover, the recent failure of the CD8 T cell-based Merck "STEP" vaccine trial in human HIV infection has alerted the community and has sparked renewed interest in complementary mechanisms that may aid immune defenses against persistent viral disease [16].

Antibodies are among the obvious candidates to complement CTL-mediated control. However, their contribution to the resolution of primary virus infections in general, and persisting ones in particular, has remained controversial. Rapid mutational escape of persisting viruses from antibody neutralization represents a major obstacle to efficient antibody-mediated control [17-21]. Moreover, observations that patients with Bruton's agammaglobulinemia can control acute viral diseases [22] helped create a generally held notion that, unlike what applies for protection against reinfection, primary viral infections were predominantly controlled by cell-mediated immunity [22]. Experiments in mice, monkeys, and man had shown that passive administration of potent nAbs or transgenic expression of a virus-neutralizing $B$ cell receptor (BCR) can prevent infection [23,24], augment virus control during infection [25-27], or prevent the establishment of persistence [28,29]. Still, these experimental observations did not challenge the above dogma since the experimental conditions chosen did not mimic the kinetics and magnitude of the host's spontaneous nAb response (delayed and weak).

Similarly, it seemed unlikely that antibodies could influence LCMV control and persistence, until B cell-deficient mice were found to control the infection only transiently, or not at all. B cell-deficient mice showed vanishing CD8 T cell function and viral recrudescence [30,31], but the conclusions became doubtful when the mice were shown to have a distorted splenic microarchitecture and intrinsically defective CD4 T cell responses [32-34]. As CD4 T cells are essential to the maintenance of effective antiviral CD8 $\mathrm{T}$ cell responses [35], the shortcomings in viral resistance were concluded to result from defective $\mathrm{T}$ help, rather than from the lack of antibody [34].
Given the outlined uncertainties, combined with the importance of such fundamental knowledge in order to refine preventive and therapeutic strategies in humans, we have readdressed the role of specific antibody responses to the control and resolution of persistent infection. We used the LCMV model to establish viral infection in genetically engineered mice that support the development of B cells, but do so only with restricted diversity and predominantly LCMV-unrelated specificity. In addition, we infected B cellsufficient mouse models, unable to mount either serum immunoglobulin M (IgM) or immunoglobulin G ( $\operatorname{IgG})$ responses. Our studies reveal that virus-specific antibodies, including early adaptive $\operatorname{IgM}$ responses, play an essential role in reducing viral loads and ultimately determine viral clearance or persistence.

\section{Results}

B Cell Receptor Diversity Correlates with the Magnitude of Antiviral Antibody Responses and Determines Efficacy of Virus Control

Using the murine model of LCMV infection, we aimed here at investigating the contribution of specific antibody to prevent persistent infection. To overcome the limitations intrinsic to B cell-deficient mouse models (i.e., distorted splenic microarchitecture with resulting defects in CD4 T cell responses), we first exploited two genetically engineered mouse models with a severely narrowed, predefined BCR repertoire of LCMV-unrelated specificity. T11 $\mu \mathrm{MT}$ [36] carry an immunoglobulin (Ig) heavy chain transgene in an IgM heavy chain-deficient background, whereas VI10YEN [37] combine an Ig light chain transgene with a knockin at the endogenous Ig heavy chain locus. Both constructs render the respective $\mathrm{B}$ cells specific for vesicular stomatitis virus (VSV) that is antigenically unrelated to LCMV (for a more detailed description of these strains, including their residual ability of generating antibody repertoire diversity, see Text S1). Unlike B cell-deficient mice, these animals exhibited a normal splenic microarchitecture in immunohistochemistry, and mounted unimpaired $\mathrm{CD} 4^{+} \mathrm{T}$ cell responses against LCMV, as determined by intracellular staining of interferon $\gamma($ IFN $\gamma$ ) upon peptide stimulation (Figure $\mathrm{S} 1$ and Text S1). We infected B cell-deficient $\mu \mathrm{MT}$ mice [38] (targeted deletion of the IgM transmembrane domain), BCR-restricted T11 $\mu \mathrm{MT}$ and VI10YEN mice, and C57BL/6 control mice with $10^{6}$ plaque-forming units (PFU) of LCMV intravenously (i.v.) (Figure 1). Unlike C57BL/6 mice that resolved viremia within $12 \mathrm{~d}, \mathrm{~T} 11 \mu \mathrm{MT}$ mice exhibiting the lowest degree of BCR diversity failed to contain the infection and-like B celldeficient $\mu \mathrm{MT}$ mice-remained viremic throughout the observation period of $96 \mathrm{~d}$ (Figure 1A). Similar, albeit lesspronounced, effects were seen in VI10YEN mice displaying a

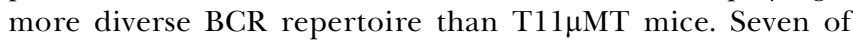
ten VI10YEN mice tested in three independent experiments exhibited protracted viremia as compared to C57BL/6 wildtype mice (Figure 1A and unpublished data). Even more pronounced was the impact of BCR diversity on the control of the more invasive Clone 13 strain of LCMV (Figure 1B). Only C57BL/6 mice succeeded in resolving viremia, whereas BCR-restricted VI10YEN and T11 $\mathrm{MT}$ mice, and B celldeficient JHT [39] mice (targeted deletion of the immunoglobulin $\mathrm{J}_{\mathrm{H}}$ locus; JHT and $\mu \mathrm{MT}$ mice were used likewise in 

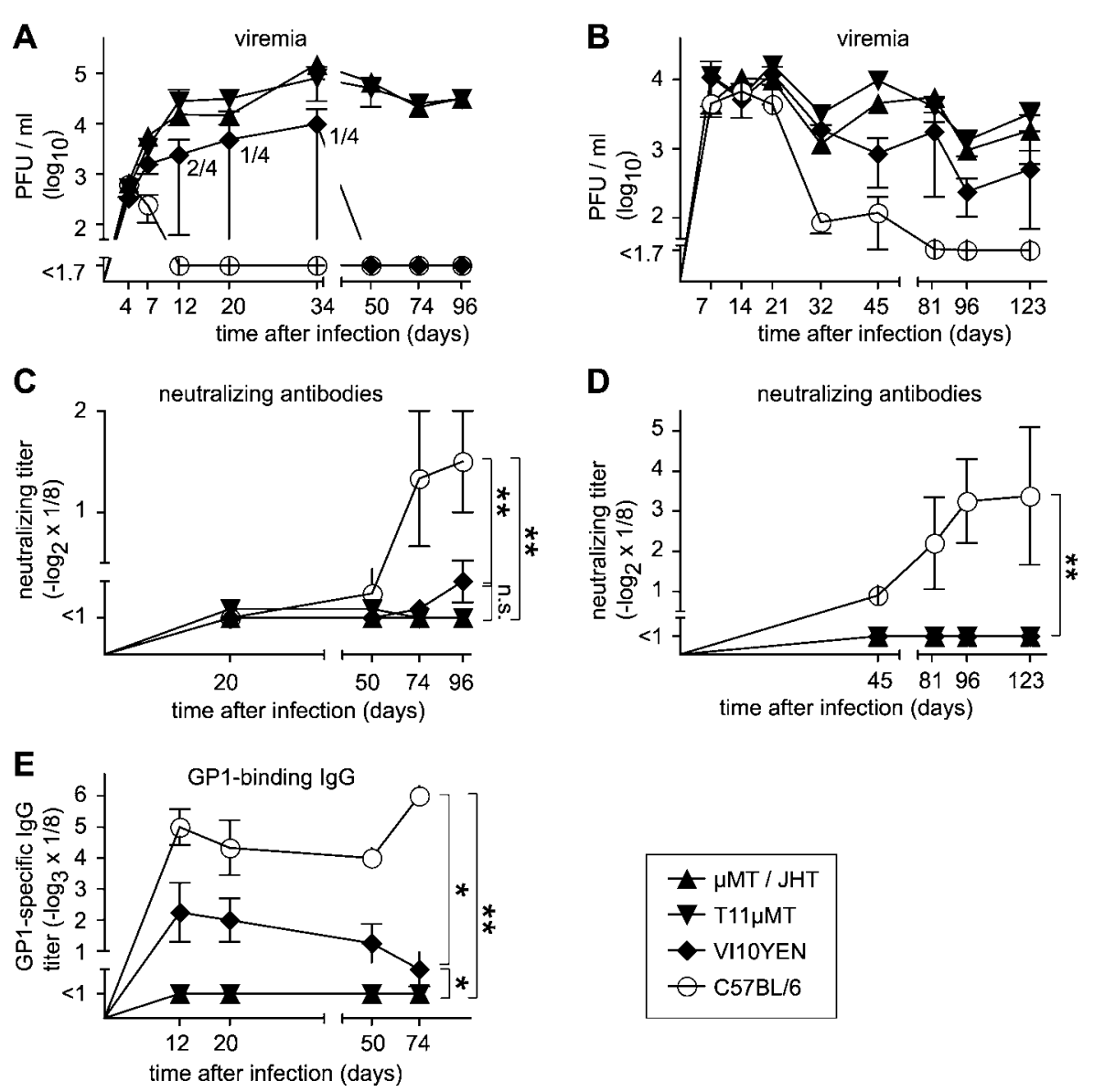

Figure 1. Viral Clearance or Persistence Depends on BCR Repertoire Diversity and Correlates with Antiviral Antibody Formation

$B$ cell-deficient ( $\mu \mathrm{MT}$ in [A, C, and E]; JHT in [B and D]), BCR-restricted T11 $\mu \mathrm{MT}$ and VI10YEN mice, and control C57BL/6 mice were infected i.v. with 10 6 PFU of LCMV-WE (A, C, and E) or $10^{6}$ PFU of LCMV Clone 13 (B and D).

(A and B) Infectious virus in blood was monitored over time. Numbers next to the VI10YEN curve in (A) indicate viremic VI10YEN mice per number of mice tested at each time point. Comparison of viral clearance kinetics (combined analysis of up to three experiments): LCMV-WE (A) C57BL/6 versus all other groups, VI10YEN versus T11 $\mu \mathrm{MT}$, VI10YEN versus $\mu \mathrm{MT}, p<0.01$. LCMV Clone 13 (B) C57BL/6 versus all other groups $p<0.05$. All other comparisons $p>0.05$.

(C and D) nAbs were monitored over time. Double asterisks $(* *)$ indicate $p<0.01$.

(E) LCMV-WE-GP1-specific IgG was measured by ELISA. Symbols represent the mean \pm SEM of four mice per group. A single asterisk $(*)$ indicates $p<$ 0.05 , and double asterisks $\left.{ }^{(* *}\right)$ indicate $p<0.01$.

For (A and C), one representative experiment of three similar experiments is shown. (E) displays one of two experiments, with symbols representing the mean \pm SEM of three to five mice per group.

doi:10.1371/journal.pbio.1000080.g001

this study) remained viremic throughout the observation period of $123 \mathrm{~d}$. Thus, BCR diversity was essential for efficient resolution of LCMV infection. Further support for this notion came from experiments in "quasimonoclonal" (QM) mice [40] with a predefined nitrophenyl-specific B cell repertoire owing to knockin of a rearranged immunoglobulin heavy chain gene in combination with an immunoglobulin light chain transgene (Figure S2). Interestingly also, the requirements for BCR diversity became apparently more stringent as the infection was prone to persistence. That is, VI10YEN mice were able to clear LCMV strain WE (LCMVWE), albeit with some delay, but they failed at resolving chronic infection with LCMV strain Clone 13. The above patterns of virus control or persistence correlated only to a limited extent with the ability of the respective mouse strains to mount a late virus-neutralizing antibody response (Figure $1 \mathrm{C}$ and 1D). In LCMV Clone 13 infection, the appearance of neutralizing serum activity around day 45 after infection coincided with viral clearance. In contrast, a clear rise in LCMV-WE-nAb occurred only between 50 and $74 \mathrm{~d}$ after infection, i.e., more than 1 mo after viral clearance from the blood. In C57BL/6 mice, this response was consistently measured although the titers varied considerably between individual animals. With further delay and barely above the detection limit of our assays, nAbs were also measured in some VI10YEN mice (Figure 1C, not statistically significant), providing only partial correlation with this mouse strain's ability to control LCMV-WE infection. In contrast, nAbs always remained below detection levels in viremic T11 $\mu \mathrm{MT}$ mice. The lack of temporal association, at least in LCMV-WE infection, between the appearance of $\mathrm{nAb}$ and clearance, prompted us to study nonneutralizing antibody (non-nAb) responses. The glycoprotein (GP) is the only surface determinant on LCMV particles. It is synthesized as a 
LCMV-WE
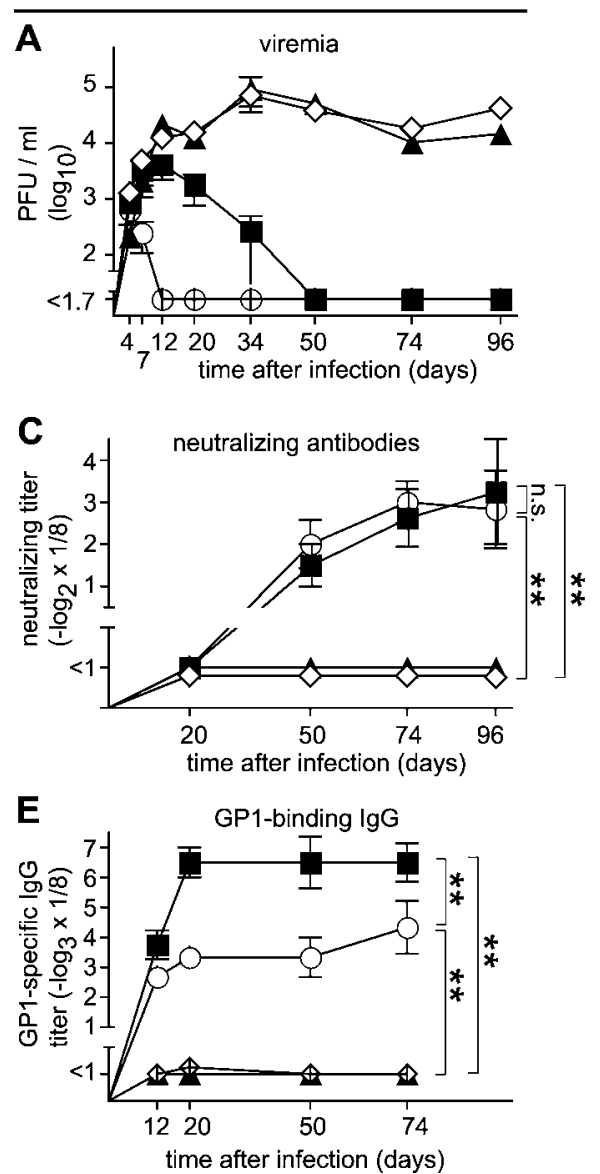

LCMV Clone 13
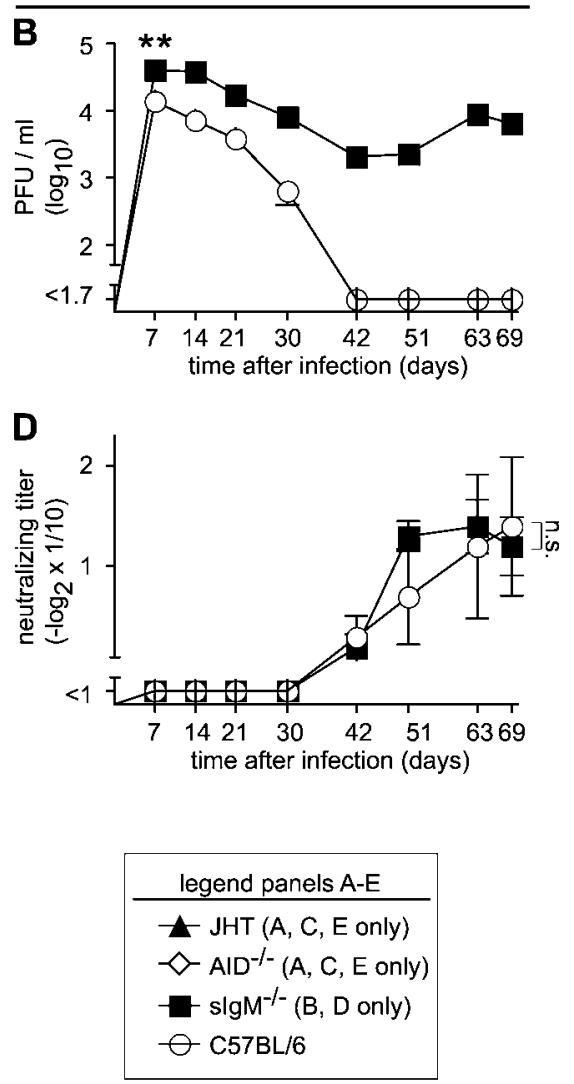

Figure 2. Virus Control Requires Secreted IgM and Also AID-Dependent Class-Switch Recombination and Affinity Maturation

(A-E) Mice of the indicated genotypes were infected with $10^{6}$ PFU of LCMV-WE (A, C, and E) or Clone 13 (B and D) i.v. Viremia (A and B), nAbs (C and D), and LCMV-WE-GP1-binding antibodies (E) were monitored over time. Symbols represent the mean \pm SEM of three to four $(A, C$, and E) or nine to ten (B

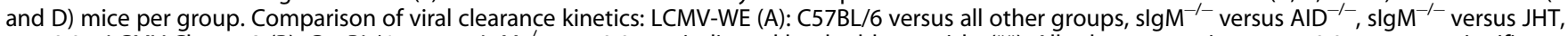
$p<0.05$. LCMV Clone 13 (B): C57BL/6 versus slgM ${ }^{-1-} p<0.01$, as indicated by double asterisks (**). All other comparisons $p>0.05$. n.s., not significant. doi:10.1371/journal.pbio.1000080.g002

precursor protein and is posttranslationally cleaved into GP1 and GP2 subunits that remain noncovalently associated [41]. GP1 makes up an outer globular domain, whereas GP2 forms a membrane-anchored stalk [41]. Hence, GP1 is accessible on the infectious virion surface, rendering this antibody specificity of particular interest. Here, we exploited recently developed ELISA techniques [42] for measuring LCMV-WE GP1-specific antibodies. By day 12 after infection, LCMV-WE evoked a GP1-specific IgG response in C57BL/6 mice and at lower titers also in V10YEN mice, but not in T11 $\mu \mathrm{MT}$ mice, correlating with virus control (Figure 1E, B cell-deficient $\mu \mathrm{MT}$ mice shown as negative controls). Thus, the timing of the GP1-binding antibody response as well as the differential magnitude in C57BL/6, VI10YEN and T11 $\mu \mathrm{MT}$ mice matched best the pattern of virus clearance.

\section{Both Adaptive IgM and IgG Are Needed for Efficient Virus Control}

Next, we assessed the individual contribution of $\operatorname{IgM}$ and IgG responses to virus control. All monoclonal LCMV nAbs characterized today are of an IgG isotype, and so is the late $\mathrm{nAb}$ response observed in the course of natural infection [27]. Hence, any potential role of antibodies in resolution of
LCMV infection had previously been accredited to IgG. To test for the role of class switch-dependent isotypes including IgG, we used gene-targeted mice lacking activation-induced cytidine deaminase $\left(\mathrm{AID}^{-1-}\right.$ ) [43]. $\mathrm{AID}^{-1-}$ mice are unable to undergo class-switch recombination and somatic hypermutation, and in our experiments, could not resolve LCMV-WE infection during the observation period of $96 \mathrm{~d}$ (Figure 2A). As expected, $\mathrm{AID}^{-1-}$ mice displayed a complete absence of nAbs and GP1-specific serum IgG (Figure 2C and 2E), suggesting that immunoglobulin class-switch recombination and IgG production together with somatic hypermutation are essential steps in the resolution of LCMV infection.

To assess a potential role of IgM antibodies we exploited the $\mathrm{sIgM}^{-1-}$ mouse model [44]. $\mathrm{sIgM}^{-1-} \mathrm{B}$ cells express IgM as their surface receptor and secrete IgG upon class-switch recombination but are unable to secrete the early IgM isotype. Experiments were carried out to confirm that according to expectations and unlike B cell-deficient $\mu \mathrm{MT}$ mice, B cell-competent $\operatorname{sIgM}^{-1-}$ mice display a normal lymphoid microarchitecture and mount unimpaired $\mathrm{CD} 4^{+} \mathrm{T}$ cell responses (Figure S3). Surprisingly, however, LCMV-WE infection resulted in substantially prolonged viremia in 

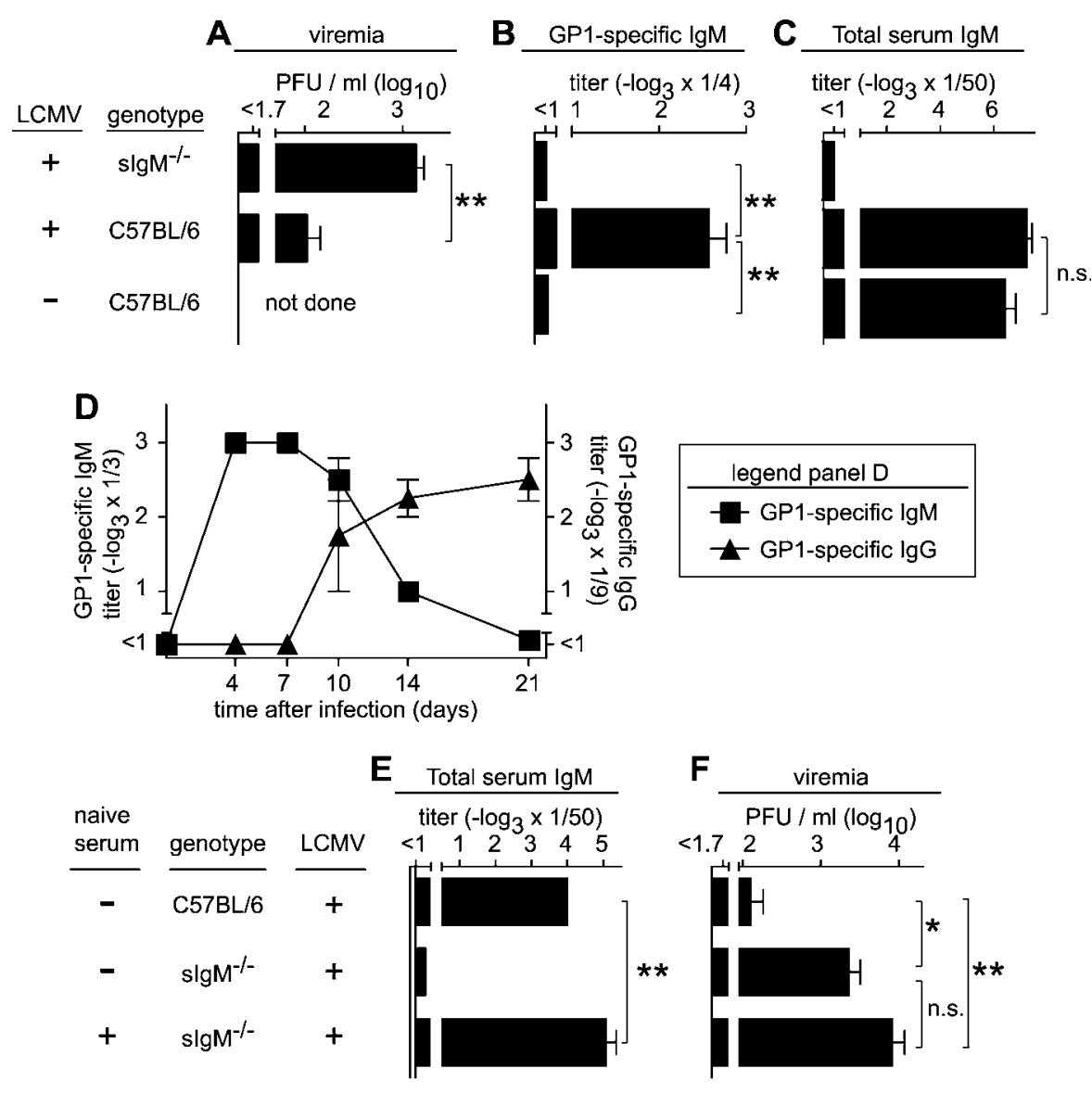

Figure 3. Early Adaptive IgM Response Rather Than Natural Antibodies Contributes to Virus Control

(A-C) $\mathrm{slgM}^{-1-}$ and C57BL/6 control mice were infected with $10^{6} \mathrm{PFU}$ of LCMV-WE i.v. Viremia (A), LCMV-WE-GP1-specific IgM (B), and total serum IgM (C) were determined $8 \mathrm{~d}$ later. Bars represent the mean \pm SEM of five to ten mice per group.

(D) C57BL/6 mice were infected with $10^{6}$ PFU of LCMV-WE i.v. LCMV-WE-GP1-specific IgM and IgG were measured over time. Symbols represent the mean \pm SEM of four mice per group.

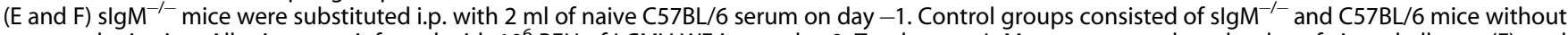
serum substitution. All mice were infected with $10^{6} \mathrm{PFU}$ of LCMV-WE i.v. on day 0 . Total serum IgM was measured on the day of virus challenge (E), and viremia was determined on day 21 (F). Bars represent the mean \pm SEM of five to twelve animals.

A single asterisk $\left(^{*}\right)$ indicates $p<0.05$, and double asterisks $\left(^{* *}\right)$ indicate $p<0.01$. n.s., not significant.

doi:10.1371/journal.pbio.1000080.g003

$\mathrm{sIgM}^{-1-}$ mice as compared to C57BL/6 control mice (Figure 2A), suggesting that contrary to expectations, an antibody response of IgM isotype contributed to virus control. More strikingly even, nine of ten $\operatorname{sIgM}^{-1-}$ mice failed to resolve LCMV Clone 13 infection for a period of at least $100 \mathrm{~d}$, whereas all nine C57BL/6 mice had cleared viremia within 42 $\mathrm{d}$ after infection (Figure 2B and unpublished data).

The analysis of $\mathrm{nAb}$ responses (measuring both IgM and IgG, Figure 2C and 2D), confirmed that the kinetics and magnitude of the $\mathrm{nAb}$ response were indistinguishable in $\mathrm{sIgM}^{-1-}$ and C57BL/6 controls, and therefore, likely were of IgG isotype as previously reported. As expected, also LCMVWE-GP1-binding IgG responses showed normal kinetics in $\mathrm{sIgM}^{-1-}$ mice. Somewhat higher GP1-specific IgG peak titers in $\mathrm{sIgM}^{-1-}$ mice as compared to C57BL/6 control mice were likely the result of prolonged viremia with an increased antigen burden (Figure 2E). In support of this notion, differences in antibody titers became particularly apparent between day 12 and 20 when C57BL/6, but not $\operatorname{sIgM}^{---}$, mice had cleared the infection. The above experiments had suggested that differences in virus loads of $\operatorname{sIgM}^{-1}$ and C57BL/6 mice were manifest as early as $1 \mathrm{wk}$ after infection $(p$ $<0.01$ for LCMV Clone 13, Figure 2B). Additional experiments corroborated this difference in early virus loads also for LCMV-WE infection (Figure 3A, $p<0.01$ ). As a likely mediator of this difference, ELISA assays detected GP1specific IgM responses in day $8 \mathrm{LCMV}-\mathrm{WE}$-infected C57BL/6, but not $\operatorname{sIgM}^{-1-}$, mice (Figure $3 \mathrm{~B}$ ), antibodies that were absent from naive C57BL/6 mouse serum (Figure 3B). Importantly also, the GP1-specific IgM responses measured here were confirmed to be entirely antigen-specific since total serum IgM (Figure 3C), unlike serum IgG [45], remained largely unaltered after LCMV infection. A time-course analysis revealed that GP1-specific IgM was highest on day 4 and 7 after infection, followed by a continuous decline of this isotype concomitant with class switch and appearance of GP1-specific IgG (Figure 3D). These assays were, however, performed with unseparated serum, and competition between IgG and IgM in ELISA may have resulted in an underestimation of IgM levels at later time points. 
A
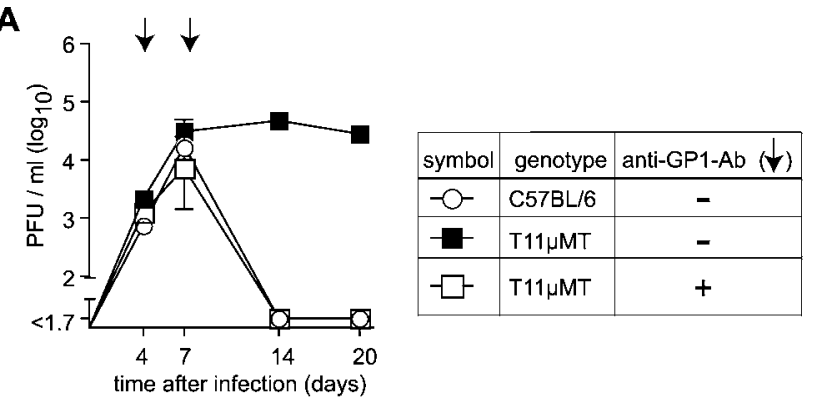

B

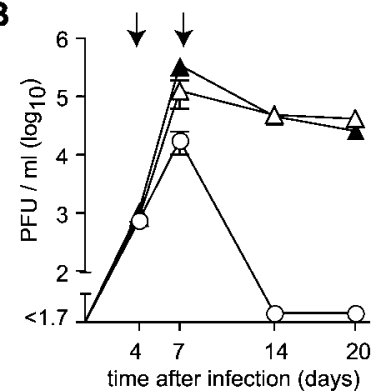

time after infection (days)

\begin{tabular}{|c|c|c|}
\hline symbol & genotype & anti-GP1-Ab $(\downarrow)$ \\
\hline-0 & C57BL/6 & - \\
\hline- & $\mathrm{TCR} \beta \delta^{-/-}$ & - \\
\hline$-\triangle$ & $\mathrm{TCR} \beta \delta^{-/-}$ & + \\
\hline
\end{tabular}

CTL activity day 7 specific killing (\%)

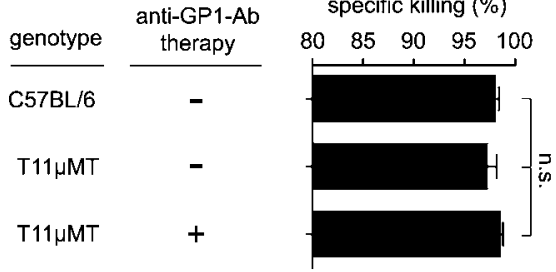

E CTL activity day 35 specific killing (\%)
D

viremia day 7 PFU / ml $\left(\log _{10}\right)$ $\begin{array}{llll}<1.72 & 3 & 4 & 5\end{array}$

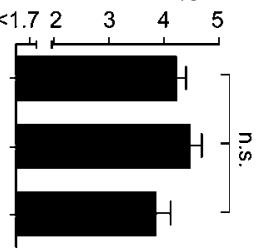

F viremia day 35 $\mathrm{PFU} / \mathrm{ml}\left(\log _{10}\right)$

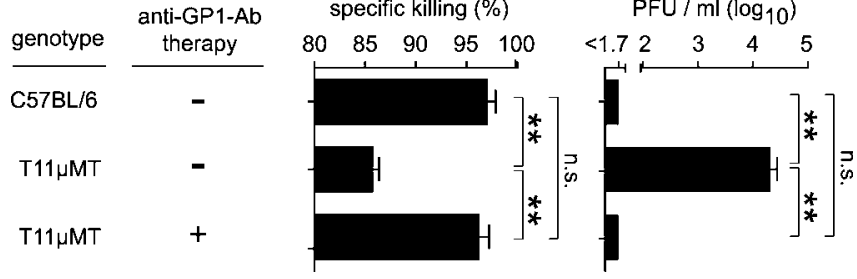

Figure 4. Antibody Therapy Prevents Viral Persistence and Preserves CTL Function in T11 1 MT Mice

(A and B) Mice of the indicated genotypes were infected with $10^{6} \mathrm{PFU}$ of LCMV WE. On day 4 and day 7 (arrows), they were treated with GP1specific antibody in normal serum or with normal serum only (control), as outlined in the chart. Viremia was monitored over time. Symbols represent the mean \pm SEM of four to five mice per group. The data in (A and $B$ ) originate from the same experiment, and the identical C57BL/6 group is shown in both graphs. Virus clearance kinetics in C57BL/6 mice and anti-GP1 antibody-treated T11 1 MT mice were indistinguishable $(p>$ $0.05)$, but each one of them differed significantly from the remaining three groups $(p<0.01)$. All other comparisons $p>0.05$.

$(\mathrm{C}-\mathrm{F}) \mathrm{C} 5 \mathrm{BL} / 6$ and T11 $\mu \mathrm{MT}$ mice were treated as in (A and B). On day 7 (C and $D)$ and day 35 ( $E$ and $F$ ) after infection, virus-specific cytotoxic activity of $C D 8^{+}$T cells was measured in an in vivo CTL assay (C and E), and virus loads were determined in blood (D and $F$ ). Bars represent the mean \pm SEM of three to five mice per group. Double asterisks $\left(^{* *}\right)$ indicate $p<0.01$. n.s., not significant.

doi:10.1371/journal.pbio.1000080.g004

$\mathrm{sIgM}^{-1-}$ mice not only lack adaptive IgM responses but also natural IgM, which contributes to control of other viral infections [46]. For dissecting the role of preexisting natural antibodies, we reconstituted $\operatorname{sIgM}^{-1-}$ mice with naive C57BL/6 mouse serum (Figure 3E). Despite reaching total serum IgM levels at least equivalent to normal C57BL/6 mice, reconstitution of natural IgM in $\mathrm{sIgM}^{-1}$ mice failed to restore virus control (Figure 3F). Taken together, these data demonstrated that adaptive $\operatorname{IgM}$ as well as $\operatorname{IgG}$ responses both played essential roles in the efficient resolution of LCMV infection. Interestingly, unaltered $\mathrm{nAb}$ kinetics in $\mathrm{sIgM}^{-1-}$ and $\mathrm{C} 57 \mathrm{BL} / 6$ control mice suggested that antiviral IgM mediated its effects by mechanisms other than classical virus neutralization.

\section{Antibody Therapy Prevents Viral Persistence and Preserves CTL Function in T11 1 MT Mice}

Next, we studied whether antibody therapy could restore virus control in BCR-restricted LCMV noncontroller mice. For this purpose, we infected T11 $\mu \mathrm{MT}$ mice with LCMV-WE and treated them on day 4 and day 7 with either normal serum (negative control) or with normal serum reconstituted with GP1-specific monoclonal antibody (Figure 4A). T11 $\mu \mathrm{MT}$ mice treated with GP1-specific antibody eliminated LCMV as efficiently as did C57BL/6 wild-type mice, whereas controltreated $\mathrm{T} 11 \mu \mathrm{MT}$ mice remained viremic, as expected (compare Figure 1A). The same antibody treatment that was

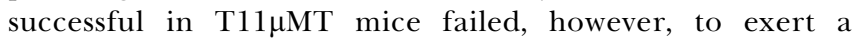
detectable effect on virus loads when administered to TCR $\beta^{-1-} \delta^{-1-}$ mice [47] lacking T cells owing to homozygous deletion of the T cell receptor $\beta$ and $\delta$ chain loci (Figure 4B). These data were compatible with the interpretation that $\mathrm{T}$

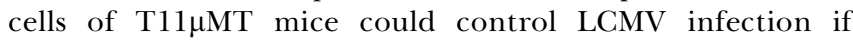
appropriately aided by specific antibodies, whereas neither $\mathrm{T}$ cells nor antibody therapy was sufficient to control LCMV on its own.

Exhaustion of CD8 T cell responses as a result of continued antigen exposure is a common observation in persistent viral infection $[48,49]$. Hence, we investigated whether antibody

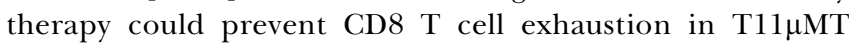
mice. The initial LCMV-specific CD8 $\mathrm{T}$ cell response of $\mathrm{T} 11 \mu \mathrm{MT}$ mice not only was of normal frequency and was functional in terms of IFN $\gamma$ secretion (Figure S1D) but also displayed an unimpaired capacity for killing antigenic cells in vivo, irrespective of antibody treatment (Figure 4C). Of note, virus loads were still similar in all groups when these tests were performed on day 7 (Figure 4D). On the contrary, defective cytolytic activity was observed in control-treated T11 $\mu \mathrm{MT}$ mice on day 35 during the chronic phase of infection. Prevention of viral persistence by antibody therapy (Figure $4 \mathrm{~F}$ ) restored in vivo cytotoxicity of $\mathrm{T} 11 \mu \mathrm{MT}$ mice to normal levels on day 35 (Figure 4E). This lent further support to the interpretation that the CD8 T cell response of T11 $\mu \mathrm{MT}$ mice was intrinsically normal, and that its decline during chronic infection was merely the result of viral persistence rather than the cause thereof. Albeit less likely, a subtle intrinsic CD8 $\mathrm{T}$ cell deficiency of $\mathrm{T} 11 \mu \mathrm{MT}$ mice cannot, however, be formally excluded. Irrespective thereof, antibody therapy may help preserve the antiviral CD8 T cell response.

Unimpaired Virus Clearance in the Absence of the Classical and Alternative Complement Cascades, of the Fc Receptor $\gamma$ Chain or of Fc $\gamma$ Receptor IIB

To evaluate the role of the classical and alternative complement cascades as major effector pathways of antibody-mediated immunity, we studied clearance of LCMV-WE in mice lacking complement components C3 and C4 

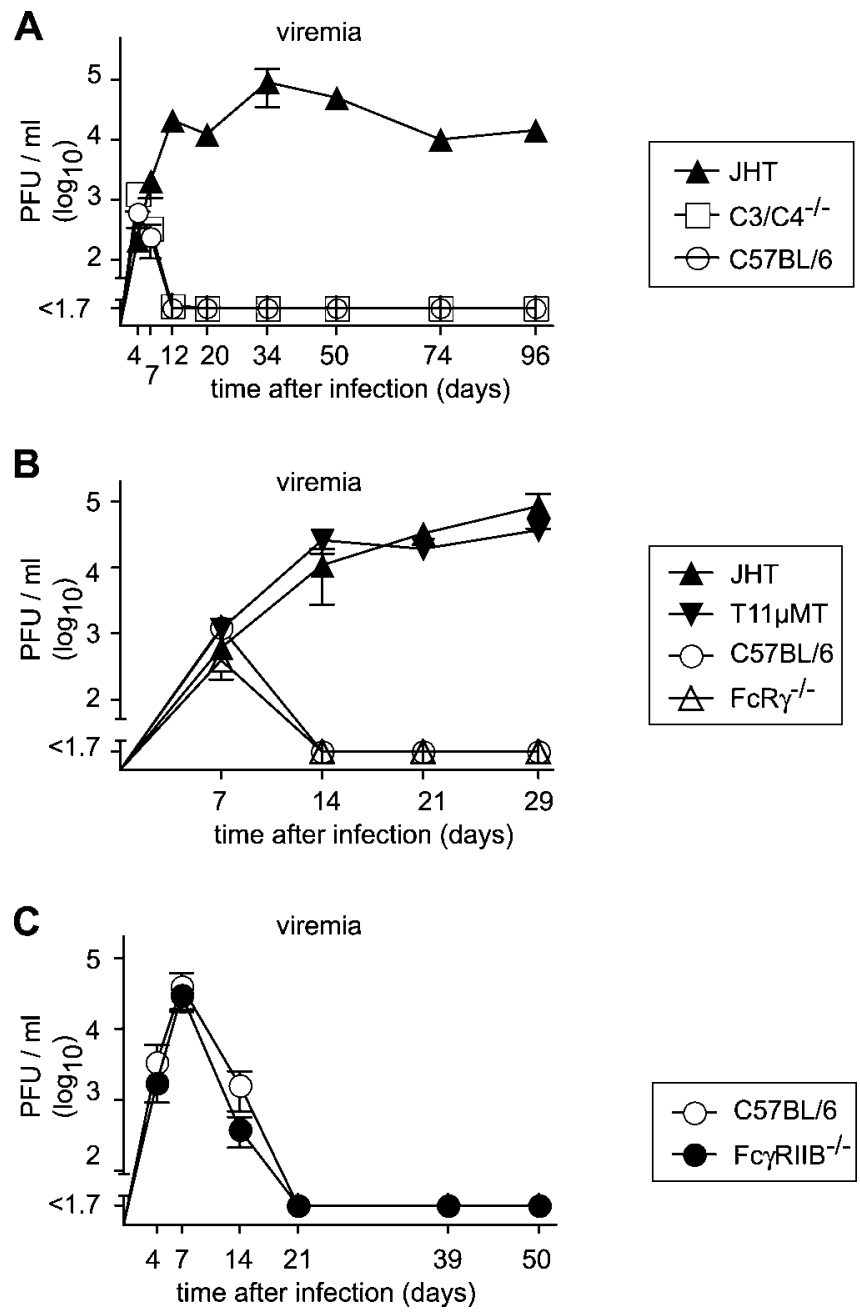

Figure 5. Efficient Virus Clearance Occurs in the Absence of Either Complement, Fc Receptor $\gamma$ Chain, or Fc $\gamma$ RIIB

Mice of the indicated genotypes were infected with $10^{6}$ PFU of LCMV$W E$, and viremia was monitored over time. Symbols represent the mean \pm SEM of three to four mice per group. $(A-C)$ represent independent experiments. $\mathrm{C}^{-1-} \mathrm{C}^{-1-}$ mice were tested alongside the experimental groups displayed in Figure $2 \mathrm{~A}, 2 \mathrm{~B}$, and $2 \mathrm{C}$, and hence the identical C57BL/6 and JHT control groups are shown in Figure $2 \mathrm{~A}$ and (A). Comparison of viral clearance kinetics: (A) C57BL/6 versus $\mathrm{C}^{-1-} \mathrm{C}^{-1-} p>$ 0.05 (not significant); $\mathrm{C} 57 \mathrm{BL} / 6$ versus JHT, $\mathrm{C}^{-1-} \mathrm{C}^{-1-}$ versus JHT $p<$ 0.05. (B) $\mathrm{C} 57 \mathrm{BL} / 6$ versus $\mathrm{FcR} \gamma^{-1-}$, JHT versus $\mathrm{T} 11 \mu \mathrm{MT} p>0.05$ (not significant); $\mathrm{C} 57 \mathrm{BL} / 6$ versus JHT, C57BL/6 versus $\mathrm{T} 11 \mu \mathrm{MT}, \mathrm{FCR}^{-1-}$ versus $\mathrm{T} 11 \mu \mathrm{MT}, \mathrm{FCR} \gamma^{-1-}$ versus JHT, $p<0.05$. (C) $\mathrm{C} 57 \mathrm{BL} / 6$ versus $\mathrm{Fc} \gamma \mathrm{RIIB}^{-1-} p>$ 0.05 (not significant).

doi:10.1371/journal.pbio.1000080.g005

$\left(\mathrm{C} 3^{--} \mathrm{C} 4^{--}\right.$mice; see Materials and Methods). $\mathrm{C}^{-1-} \mathrm{C} 4^{-l-}$ mice resolved viremia as efficiently as wild-type control mice (Figure 5A), whereas B cell-deficient JHT control mice remained viremic throughout. An analogous experiment was carried out in mice lacking Fc $\gamma$ receptors I, III, and IV owing to deletion of the common $\gamma$ chain $\left(\mathrm{FcR} \gamma^{-1-}[50]\right)$. $\mathrm{FcR} \gamma^{-1-}$ mice cleared LCMV-WE infection as efficiently as did C57BL/6 wild-type mice, whereas B cell-deficient JHT and $\mathrm{T} 11 \mu \mathrm{MT}$ mice both showed unchecked viremia throughout the observation period (Figure 5B). Unlike Fc $\gamma$ receptors I, III, and IV, Fc $\gamma$ receptor IIB (Fc $\gamma$ RIIB) expression does not depend on the common $\gamma$ chain. To study the contribution of this receptor, we infected Fc $\gamma$ RIIB -deficient mice $\left(\mathrm{Fc} \gamma \mathrm{RIIB}^{-1-}\right.$; see Materials and Methods) with LCMV, but found unimpaired virus control (Figure 5C). Taken together, these data excluded an essential individual contribution of classical and alternative complement cascades, of Fc $\gamma$ receptors I, III, and $\mathrm{IV}$, and of Fc $\gamma \mathrm{RIIB}$, respectively, in mediating protective antibody effects in the natural course of LCMV infection.

\section{Discussion}

The present data show that virus-specific antibody responses, including early IgM, play an unexpected key role in preventing viral chronicity in the CTL-controlled murine model of LCMV infection. These observations are compatible with the rapid escape from antibody recognition seen in other primarily CTL-controlled infections, including HIV and HCV [19-21], and indicate that specific antibody responses represent a level of antiviral pressure that tends to be underappreciated.

The observed antiviral effects can only be partially accredited to antibody-mediated virus neutralization. Albeit clearance of LCMV Clone 13 in C57BL/6 mice did coincide with the appearance of nAbs (compare Figure 2B and 2D), IgM effects on LCMV Clone 13 and LCMV-WE titers were evident already on day $7 / 8$ after infection (Figures 2A, 2B, and $3 \mathrm{~A})$ at a time when nAbs were undetectable even if using virtually undiluted serum for the assays (unpublished data). Similarly, LCMV-WE was cleared weeks before nAbs could be detected (compare Figure 2A and 2C). Obviously, "absence of proof" for early nAb does not equate "proof of absence," and we recognize that " $\mathrm{nAb}$ consumption" during viremia or subsequent phases of protracted clearance from tissues [51] would provide an explanation for our inability to detect nAbs. However, we favor the idea that the delay in LCMV nAb detection, relative to the antiviral effects observed, rather results from the need for time-intensive affinity maturation [42].

The protective capacity of nAbs is classically explained by "virion occupancy," i.e., sterical hindrance interfering with cell-surface receptor binding [52]. Non-nAbs, on the other hand, may mediate protection via a number of mechanisms, including: (1) virion occupancy by complement C1q binding to a virion-bound antibody [53], (2) complement cascade activation, leading to further virion occupancy through covalent opsonization, (3) complement-mediated virion lysis, (4) Fc-receptor-mediated virion phagocytosis and destruction, (5) Fc-receptor-mediated stimulation of the innate immune system, (6) immune complex formation and resulting modification of tissue distribution and cellular tropism, (7) antibody-dependent cellular cytotoxicity (ADCC), via antibody binding to viral surface proteins on infected cells, (8) impaired virus production, through antibody-mediated crosslinking of cell surface-expressed viral envelope protein [54], or (9) destruction of target protein or host cells, through antibody-mediated reactive oxygen catalysis [55]. Although a full assessment of the individual contribution of each of these potential pathways lies outside the scope and intention of the present study, we do present data ruling out a major individual contribution for covalent complement opsonization and lysis, mediated through C3 and/or C4 activation, as well as for FcR $\gamma$ - and Fc $\gamma$ RIIB-facilitated mechanisms [50,56] (Figure 5). It remains possible that another mechanism not yet experimentally addressed here may account for most of 
the antibody effects observed, e.g., Fc $\alpha / \mu$ receptor-mediated clearance [57] could explain the observed IgM effects (Figures $2 \mathrm{~A}, 2 \mathrm{~B}$, and $3 \mathrm{~A})$. However, substantial redundancy in these multiple mechanisms may render it difficult to work out the contribution of individual mechanisms including the ones we have tested here, i.e., in the absence of a specific pathway, compensation by the remaining ones may suffice for virus clearance.

The present findings are of considerable importance for our understanding of virus-host relationship in persistent infection and for refining preventive and therapeutic strategies: The success of antibody therapy in T11 $\mu \mathrm{MT}$ mice, but not in $\operatorname{TCR} \beta^{-1-} \delta^{-1}$ animals (Figure $4 \mathrm{~A}$ and $4 \mathrm{~B}$ ), suggests a synergistic effect of cellular and humoral immune defense, at least for LCMV. Antibody therapy can apparently help preserve $\mathrm{T}$ cell function, and hence early administration may be most promising. Albeit our experimental therapy was administered during a phase of infection in which $\operatorname{IgM}$ predominates (compare Figure 3D), IgG was efficient. This may be of practical importance since both vaccination and immunotherapy typically rely on IgG rather than on IgM.

Owing to structural reasons, potent nAb responses against persisting viruses are generally difficult to elicit through vaccination $[20,58]$, but non-nAbs represent an attainable goal. The present data from LCMV infection in mice strongly suggest that non-nAbs, alongside antiviral CTL responses and nAbs, can determine clearance or persistence. We suggest that non-nAbs operate by blunting the infection and thereby strengthening the efficacy of other immune mediators such as CTLs and nAbs, but also NK cells $[59,60]$. In the context of the cited literature, our data support the idea that antibodies should be considered anew in vaccination strategies aimed at combating persistent viral disease, and that aside from nAbs as a vaccine goal, non-nAbs also should be induced and assessed.

It has recently been shown that non-nAbs specific for LCMV GP-1 can mediate protective effects when expressed in a transgenic context [27]. In nontransgenic wild-type mice, we now show that virus-specific antibody responses, including GP-1-binding IgM, are not only generated rapidly (see also Figure 2G), but also exert significant antiviral pressure (compare Figure 2B and 2F; $p<0.01$ ) in the days before nAbs become detectable. Although we focused in our assays on GP-1 binding antibodies, it remains entirely possible that additional non-nAbs of alternative specificities may also contribute to the observed protective effects. Defining characteristics and specificities of "protective" and "nonprotective" non-nAbs may therefore represent an important next step in the direction of exploiting the protective capacity of non-nAbs for vaccination and immunotherapy.

Failure of the HIV AIDSVax trial eliciting mostly non-nAbs in the absence of cell-mediated immunity has somewhat dampened the hope that non-nAbs could help containing persistent infections [61,62]. Albeit non-nAbs are apparently unable to protect on their own, studies have correlated ADCC with HIV nonprogression, suggesting that non-nAbs may indeed contribute to long-term control of HIV [63]. However, much remains unclear about the overall importance of nonnAbs, and antibodies in general, to the natural course of HIV infection [64]. Moreover, the available data emphasize that the mechanisms of antibody-mediated protection do not always follow the traditional way of thinking. For instance, even a broadly HIV-neutralizing monoclonal antibody was shown to protect primarily via Fc-receptor-dependent mechanisms [65]. Of note in this context, the HIV envelope displays defective glycoproteins in great abundance [66]. Albeit unable to mediate cell entry, such defective glycoproteins are highly immunogenic and may represent efficient targets for non-nAbs. Of further importance here, non-nAbs have a relatively broad spectrum of activity against both autologous and heterologous HIV strains [67].

Taken together, the results from this study show that CD8 T cells, even if firmly established as the predominant mechanism of antiviral immune defense, need support from specific antibodies to prevail and prevent viral persistence. Given the relative ease of induction of non-nAbs (relative to nAbs), combined with the observed protective effects, our findings may provide new impetus for inclusion of antibody targets in vaccines against persistent viral diseases.

\section{Materials and Methods}

Mice and animal experiments. C57BL/6 wild-type mice, $\mu \mathrm{MT}^{-1-}$

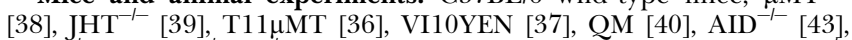
$\mathrm{sIgM}^{-1-}$ [44], $\mathrm{C}^{-1-} \mathrm{C}^{-l-}$ double-deficient mice (a crossbreed of $\mathrm{C}^{-l}$ [68] and $\mathrm{C} 4^{--}$[69] mice), $\mathrm{TCR} \beta^{-1-} \delta^{-l-}[47]$, and $\operatorname{FcR} \gamma^{--}$[50] were bred at the Institute of Laboratory Animal Science, University of Zurich, and were housed under specific pathogen-free (SPF) conditions throughout. Fc $\gamma \mathrm{RIIB}^{-l-}$ mice on a pure C57BL/6 background, in which exons 4 and 5, encoding the ligand-binding EC2 and transmembrane (TM) region, have been deleted by gene targeting in Bruce4 ES cells (C57BL/6 background), were generated in the laboratory of Sjef Verbeek. Absence of functional Fc $\gamma$ RIIB was confirmed both in functional in vivo and in vitro assays and at the protein level, as will be described elsewhere in more detail. Experiments with Fc $\gamma \mathrm{RIIB}^{--}$mice and controls were performed in a conventional mouse facility. Animal experiments were carried out at the University of Geneva and the University of Zurich with authorization by the respective cantonal authorities and in accordance with the Swiss law for animal protection.

Viruses, infection, and antibody therapy. LCMV-WE was originally obtained from F. Lehmann-Grube (Heinrich-Pette Institut, Hamburg, Germany) and was propagated on L929 cells. LCMV Clone 13 was obtained originally from R. Ahmed (Emory University, Atlanta, Georgia, United States) and was grown on BHK-21 cells. Infections were performed at a standard dose of $10^{6} \mathrm{PFU}$ by the intravenous

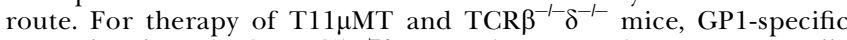
monoclonal antibody KL25 [70] was administered intraperitoneally on day $4(100 \mu \mathrm{g})$ and on day $7(1 \mathrm{mg})$, reconstituted in $400 \mu \mathrm{l}$ of normal (nonimmunized and uninfected) C57BL/6 serum. Control animals were given $400 \mu \mathrm{l}$ of normal serum.

Virus titration and detection of LCMV-neutralizing antibodies. LCMV virus stocks and blood samples were titrated by standard immunofocus assays on MC57G cells [71]. nAbs against LCMV-WE and LCMV Clone13 were measured in an immunofocus reduction assay using the respective homologous virus as described [58].

Enzyme-linked immunosorbent assays (ELISA). GP1-specific IgM and IgG responses were measured by ELISA using a GP1-Fc fusion construct produced in an eukaryotic system as described [42]. In the GP1-Fc construct, amino acids 1-265 (i.e., the GP1 domain [42]) of the LCMV-WE glycoprotein gene are fused to human Fc. As sole modification to the published method, anti-mouse IgM monoclonal antibody coupled to HRP (Sigma) was used instead of anti-mouse IgG when detecting GP1-specific IgM. Total serum IgM titers were measured in ELISA as described previously [45]. Titers displayed represent the serum dilution yielding twice background optical density values.

Enumeration of epitope-specific $T$ cell populations and in vivo CTL assay. Single-cell suspensions of splenocytes were used for intracellular cytokine assays as described [72]. Restimulation of virusspecific cells was performed for $5-6 \mathrm{~h}$ in the presence of the following synthetic peptides at $10^{-6} \mathrm{M}$ concentration: KAVYNFATC (GP33, $\mathrm{CD}^{+} \mathrm{T}$ cells), GPDIYKGVYQFKSVEFD (GP64, CD4 ${ }^{+} \mathrm{T}$ cells), and SGEGWPYIACRTSVVGRAWE (NP309, CD4 ${ }^{+} \mathrm{T}$ cells).

Cytotoxic activity of CD8 ${ }^{+} \mathrm{T}$ cells was measured in an in vivo CTL assay as previously described [73]. In brief, syngeneic C57BL/6 
splenocytes were labeled with the fluorescent dye carboxyfluorescein diacetate succinimidyl ester (CFSE) at two different concentrations (CFSE $^{\text {high }}$ or CFSE ${ }^{\text {low }}$. In addition, CFSE ${ }^{\text {high }}$ cells were pulsed with GP33 peptide at $10^{-6} \mathrm{M}$ concentration for recognition by antiviral CTLs. $3 \times 10^{7}$ cells of each population were cotransferred into virusinfected recipient mice and into naive C57BL/6 mice (control). Five hours later, the percentage of CFSE ${ }^{\text {high }}$ and CFSE ${ }^{\text {low }}$ donor cells in peripheral blood mononuclear cells was determined by flow cytometry. Specific killing was calculated as: $100-\left(\left[\left(\% \mathrm{CFSE}^{\text {high }}\right.\right.\right.$ in test animal /\% CFSE $\mathrm{CFw}^{\text {low }}$ in test animal) / (\% $\mathrm{CFSE}^{\text {high }}$ in naive /\% $\mathrm{CFSE}^{\text {low }}$ in naive) $\times 100$ ).

Immunohistochemistry. Histological analyses were performed on snap-frozen tissue. Sections were stained with rat monoclonal antibodies against murine B220 (Pharmingen), F4/80, MOMA1, and ERTR9 (all from BMA Biomedicals). Bound antibody was detected using a goat anti-rat antibody (Caltag Laboratories) and an alkaline phosphatase-coupled donkey anti-goat antibody (Jackson ImmunoResearch Laboratories) with naphthol AS-BI (6-bromo-2-hydroxy-3naphtholic acid 2-methoxy anilide) phosphate and new fuchsin as a substrate. The sections were counterstained with hemalum. For tissues of VI10YEN mice carrying a light-chain transgene with rat constant domains, reaction of anti-rat monoclonal antibody with the transgenic light chain was prevented by using an alkaline phosphatase conjugated Fc $\gamma$ fragment-specific goat anti-rat IgG antibody as a secondary antibody (Jackson ImmunoResearch Laboratories).

Statistical analysis. One-way analysis of variance (ANOVA) with the Least Significant Difference (LSD) post test was used for the comparison of individual values from multiple groups. Two-way ANOVA was performed to compare antibody responses over time. ANOVA was performed with SPSS version 13.0. Differences in individual values between two groups were analyzed by $t$-tests (unpaired, two-tailed), and virus clearance kinetics were compared in log-rank tests using GraphPad Prism software vs. 4.0b. Viral titers were log-transformed for statistical analysis, and viral clearance kinetics were compared in a Kaplan-Meier format. $p$-Values $<0.05$ were considered statistically significant; $p$-values $<0.01$ were considered highly significant.

\section{Supporting Information}

Figure S1. Normal Splenic Microarchitecture and Unimpaired CD $4^{+}$ and $\mathrm{CD}^{+} \mathrm{T}$ Cell Responses in T11 $\mu \mathrm{MT}$ and VI10YEN Mice

(A) Histological spleen sections of $\mu \mathrm{MT}$, VI10YEN, T11 $\mu \mathrm{MT}$, and C57BL/6 control mice were stained for B220 (B cells), F4/80 (red pulp macrophages), ERTR9 (marginal zone macrophages), or MOMA-1 (metallophilic marginal zone macrophages) as indicated. Each image displays a representative area of spleen from three age-matched mice per group analyzed. Magnification bars indicate $200 \mu \mathrm{m}$.

(B): Mice of the indicated genotypes were infected with $10^{6} \mathrm{PFU}$ of LCMV-WE i.v. Eight days later, epitope-specific $\mathrm{CD}^{+}$(GP64 and NP309) and $\mathrm{CD}^{+}$(GP33) $\mathrm{T}$ cell frequencies in spleen were determined in an intracellular cytokine assay. Bars represent the mean \pm the standard error of the mean (SEM) of three (GP64, NP309) or three to eight animals (GP33) per group.

\section{References}

1. Lehmann-Grube F (1971) Lymphocytic choriomeningitis virus. Virology Monographs 10. New York: Springer-Verlag. 173 p.

2. Zinkernagel RM (2002) Lymphocytic choriomeningitis virus and immunology. Curr Top Microbiol Immunol 263: 1-5.

3. Moskophidis D, Cobbold SP, Waldmann H, Lehmann-Grube F (1987) Mechanism of recovery from acute virus infection: treatment of lymphocytic choriomeningitis virus-infected mice with monoclonal antibodies reveals that Lyt-2+ T lymphocytes mediate clearance of virus and regulate the antiviral antibody response. J Virol 61: 1867-1874.

4. Leist TP, Cobbold SP, Waldmann H, Aguet M, Zinkernagel RM (1987) Functional analysis of $\mathrm{T}$ lymphocyte subsets in antiviral host defense. J Immunol 138: 2278-2281

5. Fung-Leung WP, Kundig TM, Zinkernagel RM, Mak TW (1991) Immune response against lymphocytic choriomeningitis virus infection in mice without CD8 expression. J Exp Med 174: 1425-1429.

6. Koup RA, Safrit JT, Cao Y, Andrews CA, McLeod G, et al. (1994) Temporal association of cellular immune responses with the initial control of viremia in primary human immunodeficiency virus type 1 syndrome. J Virol 68: 4650-4655.

7. Borrow P, Lewicki H, Hahn BH, Shaw GM, Oldstone MB (1994) Virusspecific CD8+ cytotoxic T-lymphocyte activity associated with control of viremia in primary human immunodeficiency virus type 1 infection. J Virol 68: 6103-6110.
Found at doi:10.1371/journal.pbio.1000080.sg001 (4.6 MB TIF).

Figure S2. Delayed Virus Clearance in Quasimonoclonal (QM) Mice Mice of the indicated genotypes were infected with $10^{6} \mathrm{PFU}$ of LCMV-WE. Viremia (A) and nAbs (B) were monitored over time. Symbols represent the mean \pm SEM of two to five mice per group. One representative experiment of two similar ones is shown. Comparison of viral clearance kinetics (combined analysis of two experiments): $\mathrm{QM}$ versus $\mathrm{C} 57 \mathrm{BL} / 6, \mathrm{QM}$ versus $\mathrm{T} 11 \mu \mathrm{MT}$, C57BL/6 versus $\mathrm{T} 11 \mu \mathrm{MT} p<0.01$.

Found at doi:10.1371/journal.pbio.1000080.sg002 (453 KB EPS).

Figure S3. Normal Splenic Microarchitecture and Unimpaired CD4 and $\mathrm{CD}^{+} \mathrm{T}$ Cell Responses in $\mathrm{sIgM}^{-1-}$ Mice

(A) Histological spleen sections of $\mathrm{sIgM}^{-1}$ were stained for B220 (B cells), F4/80 (red pulp macrophages), ERTR9 (marginal zone macrophages), or MOMA-1 (metallophilic marginal zone macrophages) as indicated. Sections of $\mu \mathrm{MT}$ and C57BL/6 mice are shown for comparison (same panels as in Figure S1A). Each image displays a representative area of spleen from three age-matched mice per group analyzed. Magnification bars indicate $200 \mu \mathrm{m}$.

(B) $\mathrm{SIgM}^{-1}$ and $\mathrm{C} 57 \mathrm{BL} / 6 \mathrm{control}$ mice were infected with $10^{6} \mathrm{PFU}$ of LCMV-WE i.v. Eight days later, epitope-specific CD4 ${ }^{+}$(GP64 and NP309) and $\mathrm{CD}^{+}$(GP33) $\mathrm{T}$ cell frequencies were determined in an intracellular cytokine assay. Bars represent the mean \pm SEM of three mice per group.

Found at doi:10.1371/journal.pbio.1000080.sg003 (5.9 MB TIF).

Text S1. Normal Splenic Microarchitecture and Unimpaired CD4+ T Cell Responses in Mice with Restricted B Cell Receptor Diversity Found at doi:10.1371/journal.pbio.1000080.sd001 (65 KB DOC).

\section{Acknowledgments}

We wish to thank Hans Hengartner and Rolf M. Zinkernagel for critical comments, suggestions, and long-term support, and PaulHenri Lambert as well as Shozo Izui for important discussions.

Author contributions. $\mathrm{AB}, \mathrm{AV}, \mathrm{ANH}, \mathrm{MH}, \mathrm{KF}, \mathrm{C}-\mathrm{AS}$, and DDP conceived and designed the experiments. $\mathrm{AB}, \mathrm{LF}, \mathrm{AV}, \mathrm{ANH}, \mathrm{MH}, \mathrm{KF}$, $\mathrm{RS}, \mathrm{EH}, \mathrm{MF}, \mathrm{AF}$, and DDP performed the experiments. AB, LF, AV, ANH, MH, KF, DM, RS, BO, C-AS, and DDP analyzed the data. BE, BMS, and JSV contributed reagents/materials/analysis tools. AB, AV, and DDP wrote the paper.

Funding. $\mathrm{AB}$ was supported by a PhD scholarship of the Boehringer Ingelheim Fonds and by a postdoctoral fellowship of the Roche Research Foundation. ANH is a fellow of GRAKO1121 of the German Research Foundation. DDP holds a stipendiary professorship of the Swiss National Science Foundation (No. PP00A114913) and was supported by grant No. 3100A0-104067/1 of the Swiss National Science Foundation.

Competing interests. The authors have declared that no competing interests exist.

8. Migueles SA, Sabbaghian MS, Shupert WL, Bettinotti MP, Marincola FM, et al. (2000) HLA B*5701 is highly associated with restriction of virus replication in a subgroup of HIV-infected long term nonprogressors. Proc Natl Acad Sci U S A 97: 2709-2714.

9. Jin X, Bauer DE, Tuttleton SE, Lewin S, Gettie A, et al. (1999) Dramatic rise in plasma viremia after CD8(+) T cell depletion in simian immunodeficiency virus-infected macaques. J Exp Med 189: 991-998.

10. Schmitz JE, Kuroda MJ, Santra S, Sasseville VG, Simon MA, et al. (1999) Control of viremia in simian immunodeficiency virus infection by CD8+ lymphocytes. Science 283: 857-860.

11. Matano T, Shibata R, Siemon C, Connors M, Lane HC, et al. (1998) Administration of an anti-CD8 monoclonal antibody interferes with the clearance of chimeric, $m$ mkjl simian/human immunodeficiency virus during primary infections of rhesus macaques. J Virol 72: 164-169.

12. Thimme R, Wieland S, Steiger C, Ghrayeb J, Reimann KA, et al. (2003) $\mathrm{CD} 8(+) \mathrm{T}$ cells mediate viral clearance and disease pathogenesis during acute hepatitis B virus infection. J Virol 77: 68-76.

13. Shoukry NH, Grakoui A, Houghton M, Chien DY, Ghrayeb J, et al. (2003) Memory CD8+ T cells are required for protection from persistent hepatitis C virus infection. J Exp Med 197: 1645-1655

14. Pereyra F, Addo MM, Kaufmann DE, Liu Y, Miura T, et al. (2008) Genetic and immunologic heterogeneity among persons who control HIV infection in the absence of therapy. J Infect Dis 197: 563-571.

15. Emu B, Sinclair E, Hatano H, Ferre A, Schacklett B, et al. (2008) HLA class I- 
restricted $\mathrm{T}$ cell responses may contribute to the control of HIV infection, but such responses are not always necessary for long-term virus control. J Virol.

16. Walker BD, Burton DR (2008) Toward an AIDS vaccine. Science 320: 760-764

17. Ciurea A, Klenerman P, Hunziker L, Horvath E, Senn BM, et al. (2000) Viral persistence in vivo through selection of neutralizing antibody-escape variants. Proc Natl Acad Sci U S A 97: 2749-2754

18. Hunziker L, Ciurea A, Recher M, Hengartner H, Zinkernagel RM (2003) Public versus personal serotypes of a viral quasispecies. Proc Natl Acad Sci U S A 100: 6015-6020.

19. Richman DD, Wrin T, Little SJ, Petropoulos CJ (2003) Rapid evolution of the neutralizing antibody response to HIV type 1 infection. Proc Natl Acad Sci U S A 100: 4144-4149.

20. Wei X, Decker JM, Wang S, Hui H, Kappes JC, et al. (2003) Antibody neutralization and escape by HIV-1. Nature 422: 307-312.

21. Shimizu YK, Hijikata M, Iwamoto A, Alter HJ, Purcell RH, et al. (1994) Neutralizing antibodies against hepatitis $\mathrm{C}$ virus and the emergence of neutralization escape mutant viruses. J Virol 68: 1494-1500.

22. Sanna PP, Burton DR (2000) Role of antibodies in controlling viral disease: lessons from experiments of nature and gene knockouts. J Virol 74: 98139817.

23. Shibata R, Igarashi T, Haigwood N, Buckler-White A, Ogert R, et al. (1999) Neutralizing antibody directed against the HIV-1 envelope glycoprotein can completely block HIV-1/SIV chimeric virus infections of macaque monkeys. Nat Med 5: 204-210.

24. Gauduin MC, Parren PW, Weir R, Barbas CF, Burton DR, et al. (1997) Passive immunization with a human monoclonal antibody protects huPBL-SCID mice against challenge by primary isolates of HIV-1. Nat Med 3 : 1389-1393.

25. Seiler P, Kalinke U, Rulicke T, Bucher EM, Bose C, et al. (1998) Enhanced virus clearance by early inducible lymphocytic choriomeningitis virusneutralizing antibodies in immunoglobulin-transgenic mice. J Virol 72 : 2253-2258.

26. Trkola A, Kuster H, Rusert P, Joos B, Fischer M, et al. (2005) Delay of HIV-1 rebound after cessation of antiretroviral therapy through passive transfer of human neutralizing antibodies. Nat Med 11: 615-622.

27. Hangartner L, Zellweger RM, Giobbi M, Weber J, Eschli B, et al. (2006) Nonneutralizing antibodies binding to the surface glycoprotein of lymphocytic choriomeningitis virus reduce early virus spread. J Exp Med 203: 2033-2042.

28. Law M, Maruyama T, Lewis J, Giang E, Tarr AW, et al. (2008) Broadly neutralizing antibodies protect against hepatitis $\mathrm{C}$ virus quasispecies challenge. Nat Med 14: 25-27.

29. Bachmann MF, Hunziker L, Zinkernagel RM, Storni T, Kopf M (2004) Maintenance of memory CTL responses by Thelper cells and CD40-CD40 ligand: antibodies provide the key. Eur J Immunol 34: 317-326.

30. Thomsen AR, Johansen J, Marker O, Christensen JP (1996) Exhaustion of CTL memory and recrudescence of viremia in lymphocytic choriomeningitis virus-infected MHC class II-deficient mice and B cell-deficient mice. J Immunol 157: 3074-3080.

31. Planz O, Ehl S, Furrer E, Horvath E, Brundler MA, et al. (1997) A critical role for neutralizing-antibody-producing $\mathrm{B}$ cells, CD4 $(+) \mathrm{T}$ cells, and interferons in persistent and acute infections of mice with lymphocytic choriomeningitis virus: implications for adoptive immunotherapy of virus carriers. Proc Natl Acad Sci U S A 94: 6874-6879.

32. Homann D, Tishon A, Berger DP, Weigle WO, von Herrath MG, et al. (1998 Evidence for an underlying CD4 helper and CD8 T-cell defect in B-celldeficient mice: failure to clear persistent virus infection after adoptive immunotherapy with virus-specific memory cells from muMT/muMT mice J Virol 72: 9208-9216.

33. Morrison LA, Zhu L, Thebeau LG (2001) Vaccine-induced serum immunoglobin contributes to protection from herpes simplex virus type 2 genital infection in the presence of immune T cells. J Virol 75: 1195-1204

34. Christensen JP, Kauffmann SO, Thomsen AR (2003) Deficient CD4+ T cell priming and regression of CD8+ T cell functionality in virus-infected mice lacking a normal B cell compartment. J Immunol 171: 4733-4741.

35. Matloubian M, Concepcion RJ, Ahmed R (1994) CD4+ T cells are required to sustain CD8+ cytotoxic T-cell responses during chronic viral infection. J Virol 68: 8056-8063.

36. Klein MA, Frigg R, Flechsig E, Raeber AJ, Kalinke U, et al. (1997) A crucial role for B cells in neuroinvasive scrapie. Nature 390: 687-690.

37. Hangartner L, Senn BM, Ledermann B, Kalinke U, Seiler P, et al. (2003) Antiviral immune responses in gene-targeted mice expressing the immunoglobulin heavy chain of virus-neutralizing antibodies. Proc Natl Acad Sci U S A 100: 12883-12888.

38. Kitamura D, Roes J, Kuhn R, Rajewsky K (1991) A B cell-deficient mouse by targeted disruption of the membrane exon of the immunoglobulin mu chain gene. Nature 350: 423-426.

39. Chen J, Trounstine M, Alt FW, Young F, Kurahara C, et al. (1993) Immunoglobulin gene rearrangement in B cell deficient mice generated by targeted deletion of the JH locus. Int Immunol 5: 647-656.

40. Cascalho M, Ma A, Lee S, Masat L, Wabl M (1996) A quasi-monoclonal mouse. Science 272: 1649-1652.

41. Buchmeier MJ, De La Torre JC, Peters CJ (2007) Arenaviridae: the viruses and their replication. In: Knipe DM, and Howley PM, editors. Fields virology. 5th edition, Philadelphia: Wolters Kluwer Lippincott Williams \& Wilkins. pp. 1792-1827.

42. Eschli B, Zellweger RM, Wepf A, Lang KS, Quirin K, et al. (2007) Early antibodies specific for the neutralizing epitope on the receptor binding subunit of the lymphocytic choriomeningitis virus glycoprotein fail to neutralize the virus. J Virol 81: 11650-11657.

43. Muramatsu M, Kinoshita K, Fagarasan S, Yamada S, Shinkai Y, et al. (2000) Class switch recombination and hypermutation require activation-induced cytidine deaminase (AID), a potential RNA editing enzyme. Cell 102: 553563.

44. Boes M, Esau C, Fischer MB, Schmidt T, Carroll M, et al. (1998) Enhanced B1 cell development, but impaired IgG antibody responses in mice deficient in secreted IgM. J Immunol 160: 4776-4787.

45. Hunziker L, Recher M, Macpherson AJ, Ciurea A, Freigang S, et al. (2003) Hypergammaglobulinemia and autoantibody induction mechanisms in viral infections. Nat Immunol 4: 343-349.

46. Ochsenbein AF, Fehr T, Lutz C, Suter M, Brombacher F, et al. (1999) Control of early viral and bacterial distribution and disease by natural antibodies. Science 286: 2156-2159.

47. Mombaerts $\mathrm{P}$, Mizoguchi E, Ljunggren HG, Iacomini J, Ishikawa H, et al. (1994) Peripheral lymphoid development and function in TCR mutant mice. Int Immunol 6: 1061-1070.

48. Shin H, Wherry EJ (2007) CD8 T cell dysfunction during chronic viral infection. Curr Opin Immunol 19: 408-415.

49. Zajac AJ, Blattman JN, Murali-Krishna K, Sourdive DJ, Suresh M, et al. (1998) Viral immune evasion due to persistence of activated T cells without effector function. J Exp Med 188: 2205-2213.

50. Takai T, Li M, Sylvestre D, Clynes R, Ravetch JV (1994) FcR gamma chain deletion results in pleiotrophic effector cell defects. Cell 76: 519-529.

51. Recher M, Lang KS, Navarini A, Hunziker L, Lang PA, et al. (2007) Extralymphatic virus sanctuaries as a consequence of potent T-cell activation. Nat Med 13: 1316-1323.

52. Parren PW, Burton DR (2001) The antiviral activity of antibodies in vitro and in vivo. Adv Immunol 77: 195-262.

53. Mozdzanowska K, Feng J, Eid M, Zharikova D, Gerhard W (2006) Enhancement of neutralizing activity of influenza virus-specific antibodies by serum components. Virology 352: 418-426.

54. Fujinami RS, Oldstone MB (1979) Antiviral antibody reacting on the plasma membrane alters measles virus expression inside the cell. Nature 279: 529530 .

55. Wentworth AD, Jones LH, Wentworth P Jr, Janda KD, Lerner RA (2000) Antibodies have the intrinsic capacity to destroy antigens. Proc Natl Acad Sci U S A 97: 10930-10935.

56. Yada A, Ebihara S, Matsumura K, Endo S, Maeda T, et al. (2003) Accelerated antigen presentation and elicitation of humoral response in vivo by FcgammaRIIB- and FcgammaRI/III-mediated immune complex uptake. Cell Immunol 225: 21-32.

57. Shibuya A, Sakamoto N, Shimizu Y, Shibuya K, Osawa M, et al. (2000) Fc alpha/mu receptor mediates endocytosis of IgM-coated microbes. Nat Immunol 1: 441-446.

58. Pinschewer DD, Perez M, Jeetendra E, Bächi T, Horvath E, et al. (2004) Kinetics of protective antibodies are determined by the viral surface antigen. J Clin Invest 114: 988-993.

59. Qi Y, Martin MP, Gao X, Jacobson L, Goedert JJ, et al. (2006) KIR/HLA pleiotropism: protection against both HIV and opportunistic infections. PLoS Pathog 2: e79. doi:10.1371/journal.ppat.0020079

60. Martin MP, Gao X, Lee JH, Nelson GW, Detels R, et al. (2002) Epistatic interaction between KIR3DS1 and HLA-B delays the progression to AIDS. Nat Genet 31: 429-434

61. Check E (2003) AIDS vaccines: back to 'plan A'. Nature 423: 912-914.

62. Ready T (2003) AIDSVAX flop leaves vaccine field unscathed. Nat Med 9: 376.

63. Baum LL, Cassutt KJ, Knigge K, Khattri R, Margolick J, et al. (1996) HIV-1 gp120-specific antibody-dependent cell-mediated cytotoxicity correlates with rate of disease progression. J Immunol 157: 2168-2173.

64. Huber M, Trkola A (2007) Humoral immunity to HIV-1: neutralization and beyond. J Intern Med 262: 5-25.

65. Hessell AJ, Hangartner L, Hunter M, Havenith CE, Beurskens FJ, et al. (2007) Fc receptor but not complement binding is important in antibody protection against HIV. Nature 449: 101-104.

66. Moore PL, Crooks ET, Porter L, Zhu P, Cayanan CS, et al. (2006) Nature of nonfunctional envelope proteins on the surface of human immunodeficiency virus type 1 . J Virol 80: 2515-2528.

67. Huber M, Fischer M, Misselwitz B, Manrique A, Kuster H, et al. (2006) Complement lysis activity in autologous plasma is associated with lower viral loads during the acute phase of HIV-1 infection. PLoS Med 3: e441. doi:10.1371/journal.pmed.0030441

68. Wessels MR, Butko P, Ma M, Warren HB, Lage AL, et al. (1995) Studies of group B streptococcal infection in mice deficient in complement component C3 or C4 demonstrate an essential role for complement in both innate and acquired immunity. Proc Natl Acad Sci U S A 92: 1149011494.

69. Fischer MB, Ma M, Goerg S, Zhou X, Xia J, et al. (1996) Regulation of the B cell response to $\mathrm{T}$-dependent antigens by classical pathway complement. J Immunol 157: 549-556. 
70. Bruns M, Cihak J, Muller G, Lehmann-Grube F (1983) Lymphocytic choriomeningitis virus. VI. Isolation of a glycoprotein mediating neutralization. Virology 130: 247-251.

71. Battegay M, Cooper S, Althage A, Banziger J, Hengartner H, et al. (1991) Quantification of lymphocytic choriomeningitis virus with an immunological focus assay in 24- or 96-well plates. J Virol Methods 33: 191-198.
72. Flatz L, Bergthaler A, de la Torre JC, Pinschewer DD (2006) Recovery of an arenavirus entirely from RNA polymerase I/II-driven cDNA. Proc Natl Acad Sci U S A 103: 4663-4668.

73. Barchet W, Oehen S, Klenerman P, Wodarz D, Bocharov G, et al. (2000) Direct quantitation of rapid elimination of viral antigen-positive lymphocytes by antiviral CD8(+) T cells in vivo. Eur J Immunol 30: 1356-1363. 